\title{
Ensino superior no Brasil: a implantação da UNITINS e o uso da EaD como estratégia expansionista de uma universidade pública
}

\author{
Nelson de Luca Pretto* \\ Isabel C. Auler Pereira**
}

\section{Resumo:}

Este artigo destaca os elementos presentes no processo de implantação da Fundação Universidade do Tocantins (UNITINS), associado ao uso da tecnologias da informação e comunicação (TIC) pela oferta inicial do ensino telepresencial, que se caracterizou pela associação de recursos televisivos e tecnológicos. Tem como base a contextualização dos fatos desencadeados na UNITINS no período de sua implantação com a utilização da modalidade educativa telepresencial (e posterior a EAD) como recursos que viabilizou o acelerado processo de concepção, formulação e execução do projeto pedagógico do curso Normal Superior telepresencial, ofertado inicialmente ao estado do Tocantins e, posteriormente, para todo o território nacional. A reconstituição desse percurso histórico da UNITINS, pontuando as constantes alterações ocorridas em sua natureza jurídica, enfatiza as coincidências entre esses ajustes realizados durante o período de sua implantação e o contexto de reestruturação e ajustes do Estado brasileiro às exigências das políticas internacionais. Essas transformações deixaram marcas evidentes do atrelamento das políticas da educação superior no estado do Tocantins à política de minimização dos recursos para as universidades públicas. A contínua reestruturação da Universidade, ora como fundação pública, ora como autarquia ou fundação aberta ao capital privado e o início da oferta de cursos a distância estiveram consoantes com a agenda neoliberal adotada pelo governo estadual e com o estabelecimento de novos marcos regulatórios e de mudanças substanciais no campo da educação superior brasileira.

Palavras-chave: Ensino Superior. Universidades e faculdades-Tocantins. Políticas públicas. Ensino a distância-Tocantins.

* Professor Associado da Faculdade de Educação da Universidade Federal da Bahia. Pesquisador do CNPq. Doutor em Comunicação pela Universidade de São Paulo (USP).

** Professora da Universidade Federal do Tocantins. Doutora em Educação pela Universidade Federal da Bahia. 


\section{Introdução}

Em escrituras textuais tradicionais, a noção de passado-presentefuturo baseia-se, muitas vezes, na longevidade numérico-cronológica, com uma extensionalidade marcada no tempo e espaço. Na Fundação Universidade do Tocantins (UNITINS), todavia, o tempo e o espaço parecem estar revestidos de não-longevidades; o passado é assumido como um passado-passado numa extensão de cinco anos e o presente pode ter esse passado formando um contínuo breve. A UNITINS possui essa distensão temporal e espacial, característica esta que a inclusão das tecnologias de informação e comunicação em seus cursos de graduação parece ter salientado ainda mais.

Desde 1990, ano de sua criação, muitos conflitos e dilemas demarcaram a UNITINS como instituição de ensino superior. Além das situações advindas das esferas econômica, política e cultural, a incorporação, em seus cursos de graduação, em meados do ano 2000, de interfaces das tecnologias da informação e comunicação e a transferência de todos os seus cursos regulares de graduação para a Universidade Federal do Tocantins, em 2003, resultaram em sua completa reestruturação.

Esse texto procura destacar os elementos presentes no processo de implantação da Universidade do Tocantins (UNITINS), centrada em um modelo de educação a distância, inicialmente negado uma vez que desenhado com base na oferta inicial do ensino chamado telepresencial que se caracterizou pela associação de recursos televisivos e aparatos tecnológicos de informação e comunicação. Tem como base a contextualização dos fatos desencadeados na UNITINS no período de sua implantação e de sua expansão a partir do uso dessa modalidade educativa, incorporada pelo acelerado processo de concepção, formulação e execução do projeto pedagógico do curso Normal Superior telepresencial, ofertado inicialmente ao estado do Tocantins e, posteriormente, para todo o território nacional.

\section{A UNITINS e suas histórias}

O processo de desenvolvimento sócio-político-econômico do antigo norte-goiano decorreu, em princípio, a partir de dois fatores: das correntes 
migratórias que, em tempos remotos, se aventuraram até essa região movidas, sobretudo, por interesses exploratórios das minas de ouro, prata e cristal de rocha, pela extração do látex e criação de gado, e da pretensão de emancipação política das elites locais que desde meados do século XVII haviam percebido a conveniência de se promover a autonomia da região visando à abertura de novos espaços para as lideranças do estado de Goiás. Após décadas de exploração dos seus recursos e de embates políticos, em 1988, com a Constituição Brasileira, a nova unidade federativa fora criada: o estado do Tocantins.

O sentimento de abandono econômico-social e político que invadia a região (outra motivação para a criação do estado do Tocantins) transformou-se rapidamente em perspectivas de pujança. Um grande movimento desenvolvimentista se estabeleceu nessa região do nortegoiano. Essa euforia, todavia, em nada alterou a precária situação de um grande contingente populacional, uma vez que se resumiu à implantação de incipientes propostas de políticas públicas voltadas, de modo especial, para a formação docente, dado que a "região apresentava índices gritantes de alunos em idade escolar sem possibilidades de acesso à Educação Básica e de professores não titulados em exercício." (CASSIMIRO, 1996, p. 9).

A historiografia do norte-goiano sinaliza, todavia, que apesar dos escassos recursos destinados à região, duas das maiores cidades tocantinenses dispunham, desde 1985, de escolas superiores mantidas pelo governo do estado de Goiás: na região Norte, a Faculdade de Educação, Ciências e Letras de Araguaína (FACILA); na região central, a Faculdade de Filosofia do Norte-Goiano de Porto Nacional (FAFING). Mantida com recursos municipais, havia, ainda, a Faculdade de Filosofia e Ciências Humanas de Gurupi (FAFICH).

A Universidade do Tocantins (UNITINS), todavia, não surgiu com base nessas instituições de ensino superior; ela foi criada pelo governador Siqueira Campos, por meio do Decreto estadual $\mathrm{n}^{\circ} 252$, de 21 de fevereiro de 1990, e autorizada a funcionar pelo Decreto 2.021/90, de 27 de dezembro, do mesmo ano. As faculdades então existentes, em Porto Nacional e Araguaína, apesar de legalmente incorporadas à UNITINS desde 1990, só foram, efetivamente, agregadas a essa Universidade em 1992.

Integrando o projeto de emancipação da região, a UNITINS fora pensada como uma instituição verdadeiramente crítica e formadora, 
proficiente no papel de suscitar mentes capazes de compreender e transformar a realidade do estado. Para a concretização dessa proposta, a primeira presidente da UNITINS, Maria do Rosário Cassimiro, à frente de uma equipe de professores da Universidade Federal de Goiás (UFG), empreendeu um estudo aprofundado sobre a situação sócio-econômicocultural, educacional e financeira do Estado, visando à elaboração do Projeto Pedagógico da universidade tocantinense. Esse projeto trazia, em suas raízes, o ideal de superação dos vícios e imperfeições estruturais das instituições universitárias públicas brasileiras, a exemplo da dependência ilimitada dos cofres públicos e da natureza elitizante dos concursos vestibulares, propondo-se a criar 'uma universidade moderna, aberta e democrática'. Perseguia-se um modelo 'novo' de universidade (CASSIMIRO, 1996, p. 1012). Para tanto, deveria voltar-se às questões locais, sem deixar de privilegiar as preocupações universalistas normalmente atribuídas às instituições dessa natureza. Nos termos da, então, reitora Cassimiro, a UNITINS deveria ter "a cara do Tocantins", o que significava que a "instituição deveria ser pensada, organizada e implantada para dar respostas às necessidades do novo estado e da região Norte do Brasil, e para tanto, fora organizada num modelo multicampi." (CASSIMIRO, 1996, p. 15).

A natureza comunitária prevista para a UNITINS, com o Conselho Comunitário formado por lideranças locais com poder de deliberação sobre a estrutura superior da instituição, a criação de cursos e a escolha do titular da reitoria, apresentava-se como uma inovação para o ensino superior das regiões do Centro-Oeste e Norte do Brasil. Na tentativa de fazer frente às correlações de forças que se articulavam no estado, uma das pretensões desse Conselho Comunitário consistia em instalar uma Universidade despojada de influências político-partidárias. Esse intento, todavia, jamais se tornaria realidade, uma vez que, pouco tempo depois, no período de 1992 a 1998, a negociação política para a criação dos campi universitários e cursos, em inúmeras regiões do estado, se tornou um procedimento de rotina.

Em janeiro de 1991, com a posse do governador Moisés Avelino Nogueira, outra Comissão fora nomeada com a incumbência de realizar uma ampla consulta à sociedade sobre o financiamento da UNITINS e apresentar um dossiê técnico e administrativo sobre a sua situação no Estado. Nesse dossiê, deveriam estar expressos a concepção e o programa de implantação da UNITINS em coerência e articulação com o sistema de 
educação (FUNDAÇÃO UNIVERSIDADE DO TOCANTINS, 1991a, p. 18). Pretendia-se, com isso, reestruturar a universidade e integrá-la aos princípios do sistema educacional tocantinense.

A elaboração do projeto de reestruturação teve como subsídios estudos e informações oriundas da Assessoria de Planejamento (ASPLAN) e de consultas a segmentos organizados da sociedade que compreendiam: deputados estaduais, secretários de Estado, chefes de Gabinete e representantes da Associação de Indústria e Comércio, de confissões religiosas e instituições eclesiásticas, filantrópicas, Sindicatos (da Saúde, Educação), Colégio Estadual de Porto Nacional, Delegacia Regional de Ensino, associações de Bairro, Associação Comercial, produtores rurais, Colégio Sagrado Coração de Jesus e Escola Batista, professores e estudantes. O documento produzido por essa Comissão Especial, intitulado Projeto de Organização de um Sistema Integrado de Educação, Ciência e Tecnologia e reorganização da Universidade do Tocantins (FUNDAÇÃO UNIVERSIDADE DO TOCANTINS, 1991b), alterando o projeto inicial, sugeriu que, por meio de cursos tecnológicos capazes de interferir na realidade do estado, a Universidade cuidasse da formação profissional, da produção e transmissão de conhecimentos, da melhoria da qualidade de ensino em todos os níveis e contribuísse para o desenvolvimento econômico e social da região.

No mês de agosto de 1991, a UNITINS foi transformada em Autarquia, ${ }^{2}$ passando a integrar o Sistema Estadual de Ensino. Contradizendo as orientações da Comissão Diretora para a criação de cursos tecnológicos, a reitoria da UNITINS encaminhou as providências para a criação de uma universidade tradicional, materializada na criação dos cursos para a formação de advogados, engenheiros, administradores, arquitetos, dentre outros. Em decorrência de mediações político-ideológicas, as decisões e o gerenciamento da UNITINS ficaram sujeitos às negociações realizadas entre a esfera governamental e os diretórios e comitês partidários regionais.

Em 1992, um intenso processo de expansão da estrutura universitária foi desencadeado com a criação de inúmeros cursos e núcleos nos municípios de Araguaína, Paraíso do Tocantins, Porto Nacional, Miracema e Palmas que gerou inúmeros problemas relacionados tanto à qualidade dos cursos quanto a sua gestão acadêmico-administrativa. Como conseqüência, a UNITINS, cujo projeto de estruturação previa a implantação de uma universidade tecnológica, multicampi, com cursos distribuídos de acordo com a vocação 
sócio-econômico-cultural de cada região do Estado, assumira uma estrutura dissociada do contexto e necessidades regionais, passando a ser manejada por alianças político-partidárias e interesses de grupos políticos. ${ }^{3}$

Visando reverter essa situação, em março de 1993, a Comissão Diretora da UNITINS apresentou um novo documento em que apontava os princípios norteadores da reestruturação da Universidade que seria constituída por cinco Centros Universitários e três Centros de Extensão destinados ao atendimento à vocação e às potencialidades econômicoculturais das respectivas regiões, no período desse governo (1991-1994). Evidenciava, ainda, o referido documento que as causas do fracasso do projeto da universidade estavam centradas na resistência dos professores a mudanças, na desmotivação dos mesmos em relação às atividades de ensino, pesquisa e extensão devido a não existência de um plano de carreira, nos baixos salários, na redução do trabalho docente à atividades de sala de aula e à tarefas administrativas, na centralização da administração na sede da instituição e na precariedade da infra-estrutura física da Universidade (FUNDAÇÃO UNIVERSIDADE DO TOCANTINS, 1993).

As análises divergem quanto à lógica assumida para essa expansão da UNITINS. Documentos oficiais sinalizam diferentes explicações e justificativas para a expansão dos centros universitários e cursos, todavia, duas intenções no correr do processo de reestruturação da universidade se tornaram evidentes: por um lado, buscava-se atender aos propósitos políticos do governo estadual; por outro, procurava-se contemplar as demandas sociais efetivas. Constata-se, todavia, que a segunda alternativa foi subestimada no processo de reestruturação, tendo predominado a instalação de cursos que atendiam aos interesses e estratégias de grupos específicos em prejuízo da preparação de recursos humanos críticos e comprometidos com as demandas regionais, aptos a uma melhor compreensão e transformação da realidade.

Em novembro de 1996 mais uma alteração ocorreu: a natureza autárquica da Universidade do Tocantins foi extinta e, em substituição, foi instituída uma fundação de direito privado com vistas à implantação da Universidade Autônoma do Tocantins. Nesse momento, a Universidade transformava-se numa "instituição pública, mas não estatal", de "direito privado, mas não particular". Em outras palavras: pública, mas aberta ao capital privado e ao pagamento de mensalidades. $\mathrm{O}$ ensino pago para todos 
os seus alunos foi implantado, sendo que para os mais carentes foi instituído o crédito educativo. Diversos cursos foram assumidos pelos municípios que, também incapazes de suportar os custos, passaram a transferir o ônus para os alunos.

Um processo de acirramento em prol da gratuidade dos cursos da UNITINS se consolidou no início de 1999, levando o Governo, por meio de medidas provisórias, a oficializar, como estratégia política e publicitária, a existência de "duas" universidades: a primeira, com natureza "jurídica de direito privado, mantida por entidades públicas, particulares e com o apoio do governo do estado" - a Fundação Universidade do Tocantins (UNITINS); a segunda, a Universidade Estadual de Palmas (UNIPALMAS) que retomava os princípios da antiga UNITINS, autarquia estadual de natureza pública e gratuita. Todavia, como era esperado e anunciado, a UNIPALMAS não sairia do papel; jamais chegou a abrir uma vaga para cursos do ensino superior.

Simultaneamente a essa reorganização da universidade, o Governo estadual recorreu à mídia (televisiva e impressa) de diversas regiões do país, convidando empresários nacionais e estrangeiros a investir recursos no estado e na Universidade tocantinense. ${ }^{4}$ Esse fato fez com que diversos movimentos de resistência à privatização institucional aflorassem no meio acadêmico. Pressionado pela repercussão dos acontecimentos que galgara proporções nacionais e internacionais, pela mobilização de parlamentares e da sociedade organizada, o Governo estadual propôs a criação de uma universidade federal. Finalmente, em 23 de outubro de 2000, o Poder Executivo instituiu a Universidade Federal do Tocantins (UFT) ${ }^{5}$ e, em 21 de junho de 2002, homologou a transferência de todos os bens patrimoniais da UNITINS, por doação ou cessão, para essa instituição.

Dessa forma, em 2000, o sonho da universidade pública tocantinense migrou, definitivamente, para a Universidade Federal do Tocantins (UFT). Quanto à UNITINS, permaneceu mantida pelo Estado, iniciando nesse mesmo ano seu processo de reestruturação, buscando parceiros na iniciativa privada para a oferta exclusiva de cursos de graduação na modalidade telepresencial, de pós-graduação lato sensu e de programas diversos para atendimento às demandas de capacitação dos recursos humanos do estado do Tocantins.

A história da UNITINS, no período 1990/2003, ano em que formalmente repassou os cursos para a UFT, se constituiu como algo maior 
que uma simples história da instituição; chegou, muitas vezes, a se confundir com as próprias histórias de vida dos seus atores e co-atores que, no seu dia-a-dia, encarnaram a luta pela preservação da única instituição pública de ensino superior do Estado. O resultado desse esforço coletivo, apesar de todos os percalços, significou a oferta dezenas de cursos de graduação, da implantação da cultura de pesquisa e extensão e de programas de formação do professor-leigo em todas as regiões do Estado e, de modo especial, na região Norte, Bico do Papagaio, marcada por baixos índices de desenvolvimento sócio-econômico e com índices de analfabetismo que ultrapassavam 70\% (CASSIMIRO, 1996, p. 9). Propiciou, ainda, a inserção de representantes de seu quadro docente nas políticas de gestão do ensino público e o desenvolvimento de tecnologia e projetos para o desenvolvimento sustentado da região.

\section{A efetivação de uma história anunciada: parcerias e novas modalidades de ensino}

Em meados de 2000, a UNITINS, em decorrência do processo de federalização de seus cursos regulares, encaminhara um novo projeto: a oferta de cursos de graduação na modalidade telepresencial. ${ }^{6}$ Para tal, estabeleceu parcerias com a Secretaria Estadual de Educação, a TV Palmas e com a Sociedade Civil de Educação Continuada Ltda. (EDUCON), empresa situada no estado do Paraná.

A opção pela telepresencialidade representou, sobretudo, uma saída estratégico-legal-normativa para que os cursos telepresenciais não fossem caracterizados como educação a distância $(\mathrm{EaD})$, usufruindo, dessa forma, da prerrogativa de submetê-los à apreciação do Conselho Curador da UNITINS e do Conselho Estadual de Educação do Tocantins (CEE/TO) para fins de autorização e reconhecimento. Isso porque, de acordo com o Decreto 2.494/98, do Ministério da Educação, todos os pedidos de autorização ou reconhecimento de cursos em $\mathrm{EaD}$ deveriam ser analisados por uma Comissão de Especialistas na área do curso em questão e por especialistas em educação a distância da Secretaria de Educação Superior (SESu), mesmo que as instituições requerentes estivessem vinculadas aos conselhos estaduais.

Naquele momento, encaminhar o Projeto Pedagógico do curso Normal Superior, telepresencial, para aprovação da SESu implicava a 
apresentação de um Plano de Desenvolvimento Institucional (PDI) que explicitasse a capacidade financeira e administrativa da instituição, infraestrutura adequada aos recursos didáticos, suportes de informação e comunicação, além de qualificação acadêmica e experiência profissional de equipes multidisciplinares, exigências essas que não estavam contempladas na UNITINS. Submetido ao Conselho Estadual de Educação do Tocantins (CEE/TO), o curso Normal Superior, na modalidade telepresencial (CNST), foi autorizado, por meio do Parecer $n^{\circ} .153 / 2000$, de 28/9/2000, baseado na seguinte premissa:

Tal proposta se baseia no art. 81 da Lei $n^{\circ}$ 9394/96, 'organização de cursos ou de Instituições de ensino experimentais...' e se justifica na real necessidade de habilitar os professores da rede pública. O curso não se caracteriza em 'educação a distância', haja vista que a freqüência será controlada, exigindo-se $75 \%$ da mesma para aprovação. Haverá também a presença do Tutor para monitorar as aulas, que serão transmitidas ao vivo, em circuito fechado de $\mathrm{TV}$, às telessalas; os alunos disporão ainda de atendimento telefônico gratuito, correio eletrônico, apostilas e acesso à internet. (TOCANTINS, 2000).

Em fevereiro de 2001 foi realizado o primeiro processo seletivo para esse curso com 4.040 vagas. Seis meses após, em meados do mesmo ano, a UNITINS lançou um segundo edital para mais 10.160 vagas, totalizando, num único ano, 14.200 vagas distribuídas em 121 municípios do estado do Tocantins. ${ }^{?}$

De acordo com a proposta inicial da modalidade telepresencial, a UNITINS era responsável pela concepção, oferta do curso e realização do controle acadêmico; a EDUCON pela administração financeira, contratação, capacitação dos tutores e gestão dos contratos dos servidores; a contrapartida da Secretaria da Educação era a cessão das salas de aula dos colégios nas cidades em que o curso estava sendo oferecido e à TV Palmas, integrante do sistema estadual de ensino e ligada à Fundação Universidade do Tocantins, cabiam o provimento da infra-estrutura para a transmissão das teleaulas ${ }^{8}$ e a capacitação dos professores para a atuação nos estúdios de TV. Todavia, antes do final do $1^{\circ}$ semestre de 2001 a Secretaria Estadual de 
Educação e a TV Palmas restringiram sua participação no grupo a eventuais assessorias, ficando a administração e oferta do curso ao encargo apenas da UNITINS e EDUCON que redistribuíram as atribuições.

Em 2003, o reconhecimento do curso Normal Superior ocorreu por meio do Decreto estadual 1.841/2003, de quatro de setembro de 2003, que, retomando os termos do Parecer 153/2000, enfatizou a inovação do "uso integrado de sistemas tecnológicos e didáticos para viabilizar a interatividade no processo ensino-aprendizagem, para o atendimento das demandas sócio-culturais e educacionais da região e para a formação de professores leigos nas zonas urbanas e rurais do estado" (TOCANTINS, 2003). Ao destacar a "inovação do uso integrado de TV e recursos didáticos" o próprio Conselho Estadual de Educação do Tocantins demonstrava o desconhecimento sobre os projetos de telensino anteriormente implantados em outras regiões do país na década de 70, como o Projeto Saci, no Rio Grande do Norte, dentre outros.

Amparando o seu projeto de reestruturação, a UNITINS, por meio do Decreto estadual no 1.672/2002, apresentou novos objetivos institucionais: o fomento à prestação de serviços de ensino voltado para o desenvolvimento de métodos e processos de educação e capacitação, além da formulação e execução de programas especiais de ensino, cursos de pósgraduação, supletivos, telepresenciais, cursos direcionados à formação do quadro docente estadual e municipal e outros decorrentes de exigências e demandas do planejamento estadual ou regional, de forma direta ou por meio de parcerias com os mais diversos órgãos ou instituições.

Esse processo de mudanças por que passou a UNITINS fez com fossem incorporados à sua gestão novas formas de adequação ao mercado e se aproximasse do que Chaú (2003) denomina de uma "universidade operacional", ou seja "uma universidade voltada para si mesma enquanto estrutura de gestão e de arbitragem de contratos". Em outras palavras, foi forçada a buscar estratégias para superação de sua fragilidade financeira. Esse movimento de busca de recursos, a partir de demandas de órgãos estaduais e de projetos diversos, desviou-a de sua missão de produzir conhecimento para formar cidadãos e profissionais qualificados e comprometidos com o desenvolvimento do estado, pois “o não tocar em questões epistemológicas da universidade não significa um retorno a si, mas, antes de tudo, uma perda de si mesma." (CHAUÍ, 2003). 
Atenta às exigências legais, desde 2002, a UNITINS encaminhara ao Ministério da Educação os pedidos de credenciamento institucional e autorização para a oferta de 8.000 vagas do curso Normal Superior, na modalidade a distância, para todo o território nacional. Tais solicitações foram atendidas pela Portaria $\mathrm{n}^{\circ} 2.145$, de 16 de julho de 2004, que a credenciou pelo prazo de cinco anos e autorizou a oferta de seis mil vagas no curso Normal Superior. No art. $3^{\circ}$ da referida Portaria, o Ministério da Educação determinou "o acompanhamento do primeiro ano da oferta do curso a distância da Universidade do Tocantins, juntamente com o Conselho Estadual de Educação do Tocantins". O Conselho Curador da UNITINS também aprovou ad referendum a referida solicitação.

Em decorrência, a UNITINS, com um percurso breve de telepresencialidade, buscou novos referenciais para a implantação de cursos na modalidade a distância. Ainda no $2^{\circ}$ semestre de 2004 disponibilizou um edital para os cursos Normal Superior, Ciências Contábeis e Administração a distância, com vagas para todos os estados brasileiros e, posteriormente, no $1^{\circ}$ semestre de 2005 um novo edital para o curso de Pedagogia.

A complexidade envolvida na transformação da instituição para a oferta de cursos a distância e a velocidade com que esse processo foi instaurado na UNITINS, ampliando, no curto período de quatro anos, a oferta de cursos para todo o território nacional, agregando milhares de alunos nos cursos de graduação, através das modalidades telepresencial e de educação a distância, gerou entre alguns docentes o consenso sobre a premência de aprofundamento teórico sobre o novo modelo educativo adotado pela instituição. O discurso da UNITINS e EDUCON para justificar a configuração da universidade para a oferta de cursos telepresenciais e a distância embasava-se na promoção da inclusão e acesso à formação em nível superior a milhares de pessoas dos mais diversos rincões brasileiros. Todavia, esse argumento não foi plenamente aceito pelos professores da instituição. Em decorrência disso, intensificou-se na UNITINS uma prática de pesquisa e reflexão teórica, com a realização de dissertações e teses sobre a temática ${ }^{9}$ e com a intensificação desse debate internamente.

\section{Alguns modelos e práticas: a chegada da EaD}

A reconstituição desse percurso histórico da UNITINS, pontuando as constantes alterações ocorridas em sua natureza jurídica, enfatiza as 
coincidências entre esses ajustes realizados durante o período de sua implantação e o contexto de reestruturação e ajustes do Estado brasileiro às exigências das políticas internacionais. Essas transformações deixaram marcas evidentes do atrelamento das políticas da educação superior no estado do Tocantins à política de minimização dos recursos das universidades públicas. A sua contínua reestruturação, ora como fundação pública, ora como autarquia ou fundação aberta ao capital privado, esteve consoante à agenda neoliberal adotada pelo governo estadual e com o estabelecimento de novos marcos regulatórios e de mudanças substanciais no campo da educação superior brasileira.

Ao longo dos últimos anos, de modo especial, após a promulgação da Lei de Diretrizes e Bases Nacionais - LDB 9.394/96, foram inúmeras as mudanças das políticas públicas para as universidades brasileiras e, como não poderia deixar de ser, no Tocantins, essas reformas foram gradativamente implantadas por meio da redução dos aportes financeiros de custeio da Fundação Universidade do Tocantins. Em decorrência, a UNITINS vivenciou um árduo processo de busca de recursos junto a fontes públicas e privadas, de prestação de serviços a órgãos governamentais e de realização de consultorias a empresas e implantou a cobrança de mensalidades nos cursos de graduação, pós-graduação lato sensu e de extensão. Posteriormente, buscou parceiros na iniciativa privada para que pudesse dar continuidade às suas atividades universitárias e, nesse contexto, surgiu o curso Normal Superior (CNS) na modalidade telepresencial. Não houve, todavia, um debate interno sobre as implicações dessas opções, principalmente devido ao distanciamento, que era notório, no início do ano 2000 dos professores em relação às questões internas da Universidade, motivado, principalmente, pelo desgaste em face de tantas lutas travadas em vão frente ao governo estadual, para quem "autonomia universitária" era uma expressão aparentemente vazia de significado, mas repleta de intencionalidades. ${ }^{10}$

Apesar de alguns professores integrantes da equipe da Pró-Reitoria Acadêmica, nessa época, se manifestarem contrários à transferência do lócus de formação de professores para o curso Normal Superior, visto que isto representava uma retomada da formação conteudista e pragmática do ensino Normal Médio, e à oferta de cursos telepresenciais, estas decisões representavam, na perspectiva da reitoria, a possibilidade de se manter os cursos de formação de professores na Universidade. Os professores para 
o curso telepresencial passaram a ser contratados, semestralmente, pela UNITINS, de acordo com as áreas das disciplinas oferecidas no período letivo. Embora o projeto pedagógico do curso explicitasse que todos os professores deveriam ter a titulação de mestres e doutores, esse objetivo não foi alcançado, por razões diversas e justificadas: além do desafio de o professor ter que se inserir em uma nova modalidade de ensino, o contrato de prestação de serviço limitado ao semestre letivo não garantia ao professor a continuidade do trabalho.

No início do $1^{\circ}$ semestre de 2001, o curso Normal Superior, na modalidade telepresencial, passou a ser oferecido a milhares de alunos de oitenta e dois municípios tocantinenses e, presencialmente, nos Centros de Formação de Professores de Tocantinópolis e Miracema (CEFOPES) e nos campi de Arraias e Palmas. Os alunos presenciais usufruíam da gratuidade do curso, enquanto que na modalidade telepresencial havia a cobrança de mensalidades. A opção pela oferta do curso Normal Superior tornava evidente a política educacional do Estado que sinalizava, há tempo, a intenção de reduzir sua participação no custeio do ensino superior, uma vez que, em consonância com o Parecer 115/99, do Conselho Nacional de Educação as exigências legais para esse curso são menores em relação à titulação do corpo docente e infra-estrutura institucional. Além disso, as diretrizes curriculares para o curso Normal Superior, ao tomarem como base os fundamentos da Educação Básica, retiram do processo de formação, tanto das disciplinas específicas da docência, quanto da área de fundamentos educacionais, a "pesquisa e a produção de conhecimento", assumindo um caráter técnico e instrumental. O projeto de formação de professores, nessa perspectiva, restringe a formação do professor ao mínimo indispensável, ou seja, à sua preparação para lecionar nos anos iniciais do Ensino Fundamental por meio do domínio das competências básicas para o ensino de: língua portuguesa, matemática, ciências naturais, história e geografia. Tais características apontam, indubitavelmente, para a constituição de uma instituição formadora de caráter "pós-médio" e não superior, apresentando como horizonte o aligeiramento da formação pelo rebaixamento das exigências e das condições de formação. Apresenta-se em consonância com "as orientações do Banco Mundial, no sentido de privilegiar uma formação mais barata que privilegia a capacitação em serviço, a distância e em cursos mais rápidos." (FONSECA, 1998, p. 73). 
Todas essas motivações econômicas e políticas, dentre outras, contribuíram para que milhares de vagas para o curso Normal Superior, na modalidade telepresencial, continuassem a ser disponibilizadas pela UNITINS/EDUCON até 2004, quando foi implantada a modalidade a distância.

\section{A modalidade a distância na UNITINS: fundamentos e mo- tivações}

Para melhor situar os fundamentos e motivações da opção da UNITINS pelo modelo educativo a distância, a partir de 2005, abordamos, inicialmente, alguns aspectos relacionados à concepção da modalidade telepresencial que antecedeu e que, de certa forma, fundamentou, posteriormente, a implantação da modalidade a distância.

O documento que fundamenta a implantação da educação telepresencial no estado do Tocantins denominado Subsídios de Credenciamento da Fundação Universidade do Tocantins para oferecer cursos de graduação na modalidade a distância (NASCIMENTO, 2000) foi elaborado por uma equipe técnica da UNITINS, ${ }^{11}$ sob o comando de Sérgio Nascimento que, nesse momento, respondia pelas questões orçamentárias e de planejamento da universidade. Os pressupostos presentes nesse documento estão centrados nas experiências brasileiras que utilizaram multimeios associados à TV, como o "Telecurso 2000" e a "TV Escola" e em dados coletados no $1^{\circ}$ Simpósio Mundial em Teleducação, realizado pela International Telecommunication Union (ITU) em Manaus, em julho de 2000, que passaram a integrar, literalmente, a proposta. Essa equipe não chegou a elaborar o projeto pedagógico do curso, mas limitou-se a sinalizar as diretrizes gerais para a implantação da modalidade educativa a distância da UNITINS a partir do uso de multimeios, computador, internet (correio eletrônico, fóruns, biblioteca virtual entre outros). Aprofundou, todavia, questões relacionadas aos recursos orçamentários e à estrutura tecnológica necessária para a sua implantação, localização estratégica das telessalas, parcerias e orientações gerais sobre os materiais impressos, oferta das teleaulas, dentre outros pontos. Na percepção de Nascimento (2000, p. 4),

esse modelo educativo a distância deveria ser abordado com os mesmos princípios pedagógicos do 
ensino presencial, pois o que se altera é o espaço entre o gerador (transmissor) e o receptor, mas não o conteúdo. Apesar de o contato aluno-professor ser a opção ideal, temos que nos preparar para a nova era da informação instantânea, que já começou a (sic) uma década, evitando edificar barreiras que possam aumentar a distância ('gap') entre os países desenvolvidos e os em desenvolvimento. A instrução é o investimento com a maior possibilidade de retorno, como demonstram as populações dos Estados Unidos, dos Tigres Asiáticos, do Japão, da China, o último emergindo para o patamar de superpotência.

Esse discurso sinaliza alguns pontos cruciais que, para nós, evidenciam claramente a compreensão de educação a distância envolvida nesse modelo educativo: superação do tempo e espaço em EaD como simples transposição 'dos princípios pedagógicos do ensino presencial para a outra modalidade'; a educação como 'instrução' e transmissão de 'conteúdos' e compreensão das tecnologias da informação e, por fim, a idéia de comunicação aplicada à educação como meio de conexão entre o elemento 'gerador' e o 'receptor'.

Além disso, embora o projeto recorresse sistematicamente ao discurso da necessidade de capacitação e titulação dos professores que atuavam na Educação Básica sem a devida titulação, ocorreu a abertura de vagas a todos os concluintes do Ensino Médio ou equivalente, independentemente de estarem atuando ou não como professores. Isso implica que as motivações dos parceiros UNITINS e EDUCON, naquele momento, extrapolavam o interesse de atendimento às políticas públicas, mas visavam, prioritariamente, ocupar um espaço no cenário educacional a partir das estratégias e lógicas do mercado. Como a concepção e a elaboração do projeto pedagógico do curso não foram discutidas com a comunidade docente, a modalidade educativa a distância vinculou-se, desde o início, diretamente à Reitoria e não a um lócus de formação de professores ou aos cursos de Pedagogia existentes nos quatro campi da UNITINS. Esse debate sequer foi realizado pelos fóruns acadêmicos.

Numa perspectiva nacional, essa estruturação da $\mathrm{EaD}$ desvinculada dos cursos de graduação oferecidos pela universidade tem se tornado freqüente, 
especialmente, nas instituições públicas. A priori, poderíamos dizer que é motivado pelas próprias políticas educacionais do Ministério da Educação que acabam subvertendo a autonomia universitária ao acenarem com editais e projetos especiais com prazo restrito para adesão. Os gestores das universidades públicas premidos pela necessidade de ampliação do acesso da população em geral ao ensino superior público e gratuito e de atendimento às metas do próprio Plano Nacional de Educação (BRASIL, 2000) vêem, por outro lado, nesses Editais a possibilidade de oferta de novos cursos, com a utilização de novas metodologias de ensino. Como conseqüência, os cursos são implantados sem que a academia faça a sua crítica e possa, a partir de princípios teóricos, filosóficos e metodológicos, discutir os referidos projetos e analisar as suas implicações sócioeducacionais e políticas. E, o que é mais grave, essa interferência retira da universidade a autonomia para discussão de seus próprios projetos de formação, desconsiderando a produção científico-cultural das instâncias formadoras, contribuindo para a formação de novos guetos dentro do sistema ao restringir a possibilidade de que esses cursos partilhem da produção científica produzida pela própria universidade. Não cabe aqui uma crítica aos programas em si que estão sendo discutidos pelas universidades federais e propostos por esses convênios, mas às formas como as medidas advindas da esfera pública incidem sobre esses projetos, afastando-os dos cursos de formação, desvinculando-os da graduação regular e do conhecimento produzido pela universidade ao longo de sua existência.

\section{Algumas reflexões finais}

Apesar de todas essas ressalvas, entendemos que, no contexto das políticas públicas brasileiras voltadas para a educação, somente a partir da Lei $n^{\circ} 9.394 / 96$ e regulamentações posteriores a educação a distância passou a ser encarada como modalidade aplicável ao sistema educacional brasileiro e não mais como um simples campo dedicado aos projetos experimentais ou paliativos emergenciais em determinadas situações, como, por exemplo, para o atendimento às demandas educativas de jovens e adultos excluídos do acesso e permanência na escola regular. Os desafios não são pequenos: um milhão de professores precisam de qualificação, sendo que aproximadamente 25 mil docentes não concluíram o ensino médio; outros 
350 mil não possuem diploma universitário e mais 350 mil que, embora sejam graduados, não exercem atividades de ensino. ${ }^{12}$

Como decorrência da necessidade de se fazer frente a esses índices e de atender às metas do Plano Nacional de Educação (BRASIL, 2000), o Ministério da Educação, a partir do final da última década de 1990, tem implantado políticas públicas específicas visando à ampliação e interiorização da oferta do ensino superior no Brasil pelo estabelecimento de parcerias entre instituições credenciadas em EaD e outras IES, com o aumento da oferta de cursos de graduação em áreas tradicionais dos bacharelados e tecnologias e a oferta de cursos superiores a distância também em grandes centros, incluindo aqueles em que exista grande quantidade de cursos presenciais. Além disso, centenas de pólos da Universidade Aberta do Brasil (UAB) foram implantados, durante o ano de 2007, agregando aproximadamente 50 universidades federais. ${ }^{13}$

Fica evidente, portanto, que nos últimos anos o governo brasileiro tem buscado, de inúmeras formas, a ampliação do acesso ao ensino superior. As universidades, de modo especial as públicas, passaram a ser estimuladas a intensificarem suas atividades de ensino por meio da oferta de cursos a distância, dando início a um processo que pode ser irreversível de rompimento com o princípio da indissociabilidade entre ensino, pesquisa e extensão. Isso tem resultado em um intenso processo de massificação da educação superior no Brasil, propiciando, em muitas instituições, a precarização e privatização da produção do conhecimento científico, negligenciando o papel social da educação como espaço de investigação, discussão e difusão de projetos e modelos de organização da vida social e de garantia de direitos do cidadão.

Tal perspectiva coloca-nos diante de um grande dilema: quais os sentidos que as tecnologias assumem nesses projetos de formação? Qual concepção de educação fundamenta esses cursos? A redução das tecnologias da informação e comunicação a estratégias de $\mathrm{EaD}$, em especial para programas de certificação em larga escala, significa, indubitavelmente, a homogeneização dos processos de formação e sua submissão às leis do mercado. Distancia-se da concepção de formação como um espaço de construção coletiva, reduzindo-a à aquisição de conhecimentos técnicos, insuficientes para tornar o sujeito apto à cidadania plena. E, ainda, estando a maioria desses cursos na área de formação de professores, outras questões 
se apresentam: que papel esses professores desempenharão num futuro próximo? Serão eles capazes de contribuir para a reversão dessa situação de desigualdade que, dia-a-dia, se torna mais acentuada na sociedade contemporânea?

Estas e outras questões nos levam à reflexão sobre a necessidade de se retomar a compreensão da universidade como o espaço do saber, não consoante à mera transmissão de informação, mas como um espaço que promove permanentemente e, em todas as suas ações, a capacidade de duvidar, de pensar e criar novas idéias e práticas, nas várias áreas e regiões epistemológicas e em todas as dimensões da existência individual e coletiva. Nesse sentido, as tecnologias não podem ser tomadas como meras "ferramentas para o enriquecimento e diversificação" do processo educativo ou assumidas como meio facilitador da transmissão de conteúdos, sem qualquer preocupação quanto aos fundamentos teóricos envolvidos em sua inserção no currículo. Elas não são neutras, prontas para serem utilizadas, independentemente do trabalho que se pretenda realizar. Como afirma Martin-Barbero (1997, p. 256-257) “as tecnologias não são meras ferramentas transparentes; elas não se deixam usar de qualquer modo: são, em última análise, a materialização da racionalidade de uma 'certa' cultura e de um 'modelo global de organização do poder'."

Fala-se da necessidade de formar um cidadão pleno, mas o que se percebe é que, em muitos desses programas de formação, o conceito de cidadania está esvaziado, restrito à possibilidade de obtenção de titulação de nível superior. Distancia-se, portanto, do direito à cidadania plena que pressupõe o acesso democrático à informação em todos os níveis e implica a capacidade de opção e a garantia de relações dialéticas entre direitos e deveres. Ao assegurar apenas a formação das competências mínimas para o exercício da profissão, a simples associação dos recursos tecnológicos a projetos educativos situa-se na contramão das exigências do contexto contemporâneo, uma vez que as rápidas transformações econômicas requerem uma formação técnico-científica básica e o acesso a um saber universalizante.

Requerem um trabalhador que seja capaz de posicionar-se, de abstrair conceitos, de tomar decisões e intervir; que tenha, enfim, uma capacidade analítica que dê conta de linguagens diversificadas. Mais do que 'aprender a fazer', ele deve ser formado para pensar e atuar de maneira coletiva, com 
uma visão ampla do processo produtivo. A cooperação, a participação, a responsabilidade, a organização são atributos esperados desse novo tipo de profissional que é, acima de tudo, um sujeito de produção de conhecimentos e culturas, que deve operar no coletivo e que 'pode' e 'deve' colaborar para a alteração de sua realidade.

Nessa perspectiva, os fundamentos da educação a distância não podem estar centrados no uso das tecnologias ou simplesmente nomeados pelo instrumental a que recorrem. A EaD deve ser compreendida como prática social mediatizada, uma maneira de se fazer educação, de se democratizar o conhecimento, de se disponibilizar mais uma opção aos sujeitos da ação educativa, potencializada com a utilização plena das tecnologias da informação e comunicação.

O processo de ensino e aprendizagem deve estar orientado para conhecimentos que envolvam o contexto sócio-histórico-econômicocultural dos alunos e suas representações mentais, sociais, simbólicas sobre o mundo, a escola e a sociedade. Isso significa assumir o aluno ${ }^{14} \mathrm{em}$ sua temporalidade e espacialidade e as tecnologias como 'fundamento' do currículo (PRETTO, 1996), compreendendo a educação a distância como um processo de aprendizagem de um sujeito ativo, com capacidade de autonomia, de posicionar-se frente às questões que estão postas pela sociedade. Implica, acima de tudo, propiciar ao aluno situações de aprendizagem que promovam o seu desenvolvimento cognitivo e sua formação como sujeitos capazes de discernir, contextualizar e participar desse mundo contemporâneo enquanto seres éticos, autônomos e com poder de decisão.

O percurso desenhado pela UNITINS representa, de certa forma, a concretização das políticas de ampliação do acesso ao ensino superior. Criada a partir da associação de recursos públicos e privados promoveu uma ampliação intensiva do número de vagas e o resultado não poderia ser diferente: a despolitização do ato educativo e o afastamento da possibilidade de se fazer da EaD um caminho real de socialização de conhecimentos, de democratização dos bens culturais e técnicos produzidos pela sociedade, de sociabilidade e convivência e de formação de um cidadão solidário, cooperativo e coletivo. Ao racionalizar os elementos constitutivos do ato educativo distanciou-se da relação com a natureza social do ser humano e com o universo de significações que lhe permite construir a interpretação 
do mundo real. Desconsiderou o princípio de que a construção do conhecimento é resultado de uma atividade complexa em que todas as funções intelectuais básicas tomam parte e que devem estar inseridas em um processo interativo que propicie o afloramento de uma comunidade de aprendizagem, de discurso e de prática, de tal maneira a produzir significados, compreensão, ação crítica, ou seja, a centralidade do indivíduo na construção do conhecimento.

Com isso, reforça-se a necessidade do compromisso das instituições públicas de promoverem ampla discussão sobre o projeto de formação de professores a distância e de trazerem para o centro do debate a defesa de uma política de formação do professor, como o profissional que domina o conhecimento específico de sua área e os saberes pedagógicos, em uma perspectiva de totalidade. Como afirmamos em outro texto, a universidade 'pode' e 'deve' ter uma outra função, um outro papel (PRETTO, 1996, p. 221). Não se trata apenas de garantir a universalização do seu acesso. É básico que ela promova a inclusão de cidadãos, mas como sujeitos que não apenas tenham o direito à educação, mas que opinem sobre as decisões das propostas governamentais e que possam alterar e transformar os não-lugares de decisões e de mudanças. Mais do que razões econômicas, um programa de educação a distância precisa adotar políticas que possibilitem aos indivíduos e aos grupos humanos poderem falar, expressar seus pensamentos, seus desejos e suas aspirações. Esse é, essencialmente, o grande diferencial e ao mesmo tempo o grande potencial dessas tecnologias de informação e comunicação.

\section{Notas}

1 Maior detalhamento sobre a história da UNITINS pode ser obtido nos seguintes estudos: Maia (2002), Oliveira (1996), em especial a "Introdução", p. 12-18. E, ainda, Aires (1998).

2 A Lei n 326, de 24 de outubro de 1991, reestruturou a Universidade do Tocantins transformando-a em Autarquia, pessoa jurídica de direito público. Por força do seu art. $2^{\circ}$, os objetivos principais da instituição estariam centrados no tripé ensino, pesquisa e extensão integrados na formação técnico-profissional, na difusão da cultura e na criação filosófica, científica, artística e tecnológica. Diário Oficial do Estado do 
Tocantins, Palmas, nº 172, Ano IV, de 23/10/1991 (TOCANTINS, 1991, p. 1198-1200).

3 Após a criação dos três Centros de Extensão, em 1991, nas cidades de Arraias, Guaraí e Tocantinópolis, foram criados, até 1997, mais sete Centros Universitários, ficando, pois a Universidade do Tocantins instalada em 10 cidades do estado abrigando 27 cursos, atendendo 3.900 alunos.

4 Conforme anúncio publicado pelo Correio Brasiliense, em 18 de março de 2000, o governador Siqueira Campos colocou à venda parte do patrimônio do estado, inclusive a UNITINS. O anúncio era dirigido a empresários nacionais e estrangeiros (CALAGE, 2000). Ver também Bionde (2000) na revista Caros Amigos.

5 Maior detalhamento sobre o processo de criação e transferência dos bens da UNITINS para a UFT pode ser encontrado no Decreto Federal no. 4.279/2002, de 21 de junho de 2002 (BRASIL, 2002), que dispõe sobre a organização administrativa da Fundação Universidade Federal do Tocantins e determina outras providências.

6 A palavra "telepresencial" utilizada para caracterizar a modalidade de cursos oferecidos pela UNITINS, a partir de 2001, representa a junção do prefixo grego "tele", que significa distância, e do adjetivo "presencial" visando configurar a proposta de transmissão ao vivo das teleaulas para as telessalas localizadas em quase uma centena de municípios do estado do Tocantins. Expressão semelhante ("telensino") havia sido utilizada, nos anos de 1970, no Ceará, para a oferta de cursos do Ensino Fundamental.

7 Conforme dados disponíveis no sítio da UNITINS/EDUCON em 10/10/05, no período de 2000 a 2004, graduaram-se 8.411 alunos, distribuídos em 121 municípios. Desse total, 6.106 diplomas haviam sido registrados e expedidos até essa data.

8 Teleaula é aula transmitida via TV. Esse termo "teleaula" fora utilizado no programa Telecurso 2000, criado em 1995, pela Fundação Roberto Marinho e pela FIESP, unindo e aperfeiçoando dois cursos produzidos anteriormente: o "Telecurso $2^{\circ}$ Grau", que foi ao ar em janeiro de 1978, na TV Globo (fruto da parceria da FRM com a Fundação Padre An- 
chieta, TV Cultura de São Paulo), e o “Telecurso $1^{\circ}$ Grau”, que foi ao ar em março de 1981 (resultado da parceria da FRM com o Ministério da Educação e a Fundação Bradesco).

9 Pereira (2007); Gonzalez, (2008); Rocha ([2008]); Silva (2008).

10 Matéria publicada no Centro de Mídia Independente (CMI), em 10/11/2002, por Antonio Biondi, presidente do Conselho Curador da UNITINS, tinha um entendimento peculiar do conceito de "autonomia universitária". Para ele, o fato de a universidade depender inteiramente do governo para se manter fazia com que a "ingerência do governo na sua administração econômico-financeira fosse natural”. Ele garantiu, nesse momento, que não havia nenhuma ingerência na administração acadêmica, mas que ela (a universidade) era fragilizada pela falta de estabilidade dos professores. A esse respeito, é importante destacar que dos 336 professores constantes do quadro docente da UNITINS $\left(2^{\circ}\right.$ semestre de 2002), apenas nove eram concursados; os demais tinham o contrato renovado (ou não) anualmente.

11 O documento tinha como objetivo delinear um modelo educativo a distância a ser oferecido via TV sem, contudo, fazer referência à modalidade telepresencial. O termo 'telepresencial', como afirmamos, passa a ser usado posteriormente devido à necessidade de que o curso não se configurasse como 'educação a distância' e tivesse que ser submetido à Secretaria de Ensino Superior do MEC ao invés do Conselho Estadual de Educação do Tocantins.

12 Dados divulgados no Portal Terra Educação (UM..., 2006).

13 O sistema Universidade Aberta do Brasil foi criado pelo Ministério da Educação em 2005 com o objetivo de sistematizar as ações, programas, projetos, atividades pertencentes às políticas públicas voltadas para a ampliação e interiorização da oferta do ensino superior gratuito e de qualidade no Brasil. A partir de 2007, estão sendo oferecidos 198 cursos, em 40 universidades federais e dez centros federais de educação tecnológica (CEFETs), num total aproximado de 90 mil vagas.

14 Colaborou para a produção desse artigo Darlene Almada, graduanda de Pedagogia, bolsista de Iniciação Científica (CNPq). 


\section{Referências}

BIONDI, Antonio. No centro das desatenções. Caros Amigos, São Paulo, n. [44], nov. 2002. Disponível em: <http//:www.ecomm.com.br/ carosamigos/do_site/quemsomos.asp.>. Acesso em: 14 nov. 2002.

BRASIL. Câmara de Educação Superior. Conselho Nacional de Educação. Parecer $n^{\circ} 133$ de 30 de janeiro de 2001. Esclarece quanto à formação de professores para atuar na educação infantil e nas séries iniciais do ensino fundamental. Brasília, 2001. Disponível em: <http:// www.mec.gov.br>. Acesso em: 10 mar. 2007.

BRASIL. Conselho Nacional de Educação. Parecer CNE/CP 009 de 08 de maio de 2001. Dispõe sobre as Diretrizes Curriculares Nacionais para a Formação de Professores da Educação Básica, em nível superior, curso de licenciatura, de graduação plena. Brasília, 2001. Disponível em: <http://www.mec.gov.br>. Acesso em: 10 mar. 2007.

.Resolução CNE/CP 001/2002, de 18 de fevereiro de 2002. Institui as Diretrizes Curriculares Nacionais para a Formação de Professores da Educação Básica, em nível superior, curso de licenciatura, de graduação plena. Disponível em: <http://www.mec. gov.br>. Acesso em: 18 maio 2007.

Decreto-lei $n^{\circ} 2.306$, de 19 de agosto de 1997. Regulamenta, para o Sistema Federal de Ensino, as disposições contidas no art. 10 da Medida Provisória no 1.477-39, de 8 de agosto de 1997, e nos arts. 16, 19, 20, 45,46 e $\$ 1^{\circ}, 52$, parágrafo único, 54 e 88 da Lei no 9.394 , de 20 de dezembro de 1996, e dá outras providências. Brasília, 1997. Disponível em: <http://www.mec.gov.br>. Acesso em: 29 out. 2007.

Decreto-lei $n^{\circ} 2.494$ de 10 de fevereiro de 1998. Regulamenta o Art. 80 da LDB (Lei n. ${ }^{\circ}$ 9.394/96). Brasília, 1998. Disponível em: <http:// portal.mec.gov.br/seed/arquivos/pdf /tvescola/leis/D2494.pdf>. Acesso em: 22 mar. 2008.

Decreto $n^{\circ} 2.561$ de 27 de abril de 1998. Altera a redação dos arts. 11 e 12 do Decreto n. ${ }^{\circ}$ 2.494, de 10 de fevereiro de 1998, que regulamenta o disposto no art. 80 da Lei n. ${ }^{\circ} 9.394$, de 20 de dezembro 
de 1996. Brasília, 1998. Disponível em: <http://portal.mec.gov.br/seed/ arquivos/pdf/ tvescola/leis/D2561.pdf >. Acesso em: 24 abr. 2008.

BRASIL. Decreto n 3.860 de 09 de julho de 2001. Dispõe sobre a organização do ensino superior, a avaliação de cursos e instituições, e dá outras providências. Brasília, 2001. Disponível em: <http://portal.mec. gov.br/sesu/arquivos/pdf/DecN3860.pdf>. Acesso em: 24 abr. 2008.

Decreto n 4.279 de 21 de junho de 2002 da Presidência da República. Dispõe sobre a organização administrativa da Fundação Universidade Federal do Tocantins e determina outras providências. Brasília, 2002. Disponível em: <http://www.planalto. gov.br/ccivil_03/decreto/2002/ D4279.htm >. Acesso em: 24 abr. 2008.

. Decreto 5.773/2006. Dispõe sobre o exercício das funções de regulação, supervisão e avaliação de instituições de educação superior e cursos superiores de graduação e seqüenciais no sistema federal de ensino. Brasilia, 2006. Disponível em: < http://www.planalto. gov.br/ccivil_03/_ ato2004-2006/2006/Decreto/D5773.htm>. Acesso em: 24 abr. 2008.

Lei de Diretrizes e Bases - 9.394/96. Brasília: MEC, 1997.

Estabelece as diretrizes e bases da educação nacional. Brasilia, 1996. Disponível em: < http:// www.planalto. gov.br/ccivil_03/ leis/19394. htm>. Acesso em: 24 abr. 2008.

Lei n. ${ }^{\circ} 10.032$ de 23 de outubro de 2000 da Presidencia da República.

Institui a Fundação Universidade do Federal do Tocantins. Brasilia, 2000. Disponível em: < http://www.jusbrasil.com.br/legislacao/102447/lei10032-0>. Acesso em: 24 abr. 2008.

. Parecer n ${ }^{\circ}$ CP-115/99, de 10 de agosto de 1999. Brasília, 1999.

Dispõe sobre os institutos superiores de educação. Disponível em: $<$ http://portal.mec.gov.br/index.php?option $=$ com_ $_{-}$ content\&task $=$ view\&id $=333>$. Acesso em: 24 abr. 2008.

. Parecer 133/2001. Brasília, 2001. Disponível em: <http://www. mec.gov.br.>. Acesso em: 17 maio 2007.

BRASIL. Plano Nacional de Educação. Brasília: MEC, 2000.

. Portaria $n^{\circ} 301$ de 07 de abril de 1998. Normatiza os procedimentos de credenciamento de instituições para a oferta de cursos 
de graduação e educação profissional tecnológica a distância. Brasília, 1998. Disponível em: < http:// portal.mec.gov.br/seed/arquivos/pdf/ tvescola/leis/port301.pdf >. Acesso em: 24 abr. 2008.

Port. MEC n $n^{\circ} 2.145$ de 16 de julho de 2004 da Presidência da

República. Credencia a Universidade em educação a distância e autoriza a oferta do curso Normal Superior em EaD, com 6000 vagas. Diário Oficial da União, Brasilia, 20 jul. 2004, Seção 1, p. 99. Disponível em: < http:// www.inep.gov.br. DO>. Acesso em: 27 mar. 2007.

CALAGE, Elói. No grotão dos marqueteiros. Insight Inteligência, Rio de Janeiro, ano 3, n. 11, out./dez. 2000. Disponível em: <http://www. insightnet.com.br/ inteligência / m0711.htm.>. Acesso em: 4 nov. 2002.

CASSIMIRO, Maria do Rosário. Uma universidade para o Tocantins. Goiânia: Kelps, 1996.

CHAUÍ, M. A universidade pública sob nova perspectiva. In: REUNIÃO ANUAL DA ASSOCIAÇÃO NACIONAL DE PÓS-GRADUAÇÃO E PESQUISA EM EDUCAÇÃO, 26., Poços de Caldas. Anais... Poços de Caldas, MG, 2003. Disponível em: <http://www.anped.com.br>. Acesso em: 17 ago. 2005. Conferência de Abertura.

FONSECA, Marília. O Banco Mundial como referência para a justiça social no terceiro mundo: evidências do caso brasileiro. Revista Faculdade de Educaşão, São Paulo, v. 24, n. 1, p. 37-69, jan./jun.1998. FUNDAÇÃO UNIVERSIDADE DO TOCANTINS. Projeto de criação da Universidade do Tocantins: plano de expansão. Palmas, TO, 1990.

Projeto de criação da Universidade do Tocantins: uma síntese.

Tocantins, 1991a.

Projeto de organização de um Sistema Integrado de Educação, Ciência e Tecnologia e reorganização da Universidade do Tocantins. Palmas, To, 1991b. Relatório executivo: cinqüenta dias de UNITINS. Palmas, TO, 1993.

GONZALEZ, M. Lourdes Aires. A formação de professores para o ensino fundamental e médio, na Universidade do Tocantins: uma avaliação preliminar do período 1988-1996. 1998. Dissertação (Mestrado em Educação)Faculdade de Educação, Universidade Federal de Goiás, Goiás, 1998. 
GONZALEZ, M. Lourdes Aires. A telepresencialidade educativa no Tocantins: finalizações de uma trajetória em construção. 2008. Tese (Doutorado em Educação). Área de Concentração: Educação, Sociedade e Práxis Pedagógica. Universidade Federal da Bahia, Bahia, 2008.

MAIA, M. Zoreide Brito. Poder político, universidade pública e o movimento docente no Tocantins: entre a realidade e o sonho. 2002. Dissertação (Mestrado em Educação)- Faculdade de Educação, Universidade Federal de Goiás, Goiás, 2002.

MARTIN-BARBERO, Jesús. Dos meios às mediaģões. Rio de Janeiro: Editora UFRJ, 1997, p. 256-257.

NASCIMENTO, Sérgio. Subsídios de credenciamento da Fundação Universidade do Tocantins para oferecer cursos de graduação na modalidade a distância. Palmas, To: Universidade do Tocantins, 2000.

OLIVEIRA, J. M. M. de. Estudo das possibilidades de democratização do acesso ao ensino superior. o caso do Tocantins. 1996. Dissertação (Mestrado em Educação)- Centro de Educação, Universidade Federal de Pernambuco, Recife, 1996.

PEREIRA, Isabel C. A. Apreensões e apropriações do tempo e espaço na educação a distancia da UNITINS. 2007. Tese (Doutorado em Educação). Área de Concentração: Educação, Sociedade e Práxis Pedagógica. Universidade Federal da Bahia, Bahia, 2007.

PRETTO, Nelson de Luca. Uma escola sem/ com futuro: educação e multimídia. 4. ed. São Paulo: Papirus, 1996.

PRETTO, Nelson de Luca. (Org.). Globalização \& educação: mercado de trabalho, tecnologias de comunicação, educação a distância e sociedade planetária. Ijuí: Unijuí, 1999.

ROCHA, J. Damião T. Pedagogia e tecnologias digitais. [2008]. Tese (Doutorado em Educação). Área de Concentração: Educação, Sociedade e Práxis Pedagógica. Universidade Federal da Bahia, Bahia [2008]. Tese em fase de elaboração.

SILVA, Valdirene Cássia. Corpos híbridos em mentes diáfanas: as tribos urbanas e as inter(ações) com as tecnologias da informação e comunicação no universo escolar. 2008. Dissertação (Mestrado em 
Educação). Área de Concentração: Educação, Sociedade e Práxis Pedagógica. Universidade Federal da Bahia, Bahia, 2008.

TOCANTINS. Decreto n ${ }^{\circ} 252$ de 21/02/1990 do Governo do Tocantins. Cria a Universidade do Tocantins. Diário Oficial do Estado, Tocantins, D.O. E, n 54, ANO II, de 31 de dezembro de 1990.

Decreto n 2021 de 27 de dezembro de 1990 do Governo do Tocantins. Autoriza o funcionamento da Universidade do Tocantins (UNITINS). Diário Oficial do Estado, Tocantins, Publicado no D.O. E, n. 54, ANO II, de 31 de dezembro de 1990.

Lei no 326 de 23 de outubro de 1992 do Governo do Tocantins.

Reestrutura a Universidade do Tocantins transformando-a em Autarquia integrada ao Sistema Estadual de Ensino. Diário Oficial do Estado, Tocantins. D.O.E. n. 172, Ano IV, de 23 de outubro de 1992.

Parecer $n^{\circ}$ 153/2000 de 28/09/2000. Autoriza o curso Normal Superior, na modalidade telepresencial na UNITINS. Diário Oficial do Estado, Tocantins, D.O.E, nº 988, Ano XII, de 10 de novembro de 2000.

.Decreto estadual n ${ }^{\circ} 1.841 / 2003$ de 04 de setembro de 2003 . Reconhece o curso Normal Superior da Fundação Universidade do Tocantins. Diário Oficial do Estado, Tocantins, D.O.E. no 1529. Ano XV, de 30 de setembro de 2003.

UM milhão de professores precisam de qualificação diz MEC. In: PORTAL Terra Educação, 14 nov. 2006. Disponível em:<http:// www. terra.com.br>. Acesso em: 16 nov. 2006. 


\section{Higher Education in Brazil: the implantation of UNI- TINS and the use of EAD as an expansionist strategy for a public university}

\section{Abstract:}

This article highlights elements in the implantation of the University Foundation of Tocantins (UNITINS) associated to the use of information and communication technologies through the initial offer of "tele-presential" teaching, which is characterized by the association of televisable and technological resources. It is based on the contextualization of the events that took place at UNITINS in the periods of its implantation with the use of a tele-presential educational modality (and later Distance Education) as resources that make viable the accelerated process of conception, formulation and execution of the pedagogic project of the tele-presential Normal Superior course, initially offered in Tocantins State and later in the entire country. The reconstitution of this historic route at UNITINS, identifying the constant changes in its legal nature, emphasizes the coincidences between the adjustments made during the period of its implantation and the context of restructuring and adjustments of the Brazilian State to the demands of international policies. These transformations leave clear marks of the ties of higher education in Tocantins to a policy of minimization of resour-

\section{Enseñanza superior en Brasil: la implementación y el uso de la Educación a Distancia como estrategia expansionista de una Univer- sidad pública}

\section{Resumen:}

El presente artículo destaca los elementos presentes en el proceso de implementación de la Fundación de la Universidad de Tocantins (UNITINS), asociado a la utilización de tecnologías de la información y comunicación (TIC) a través de la oferta inicial de la enseñanza tele-presencial que se caracterizó por la asociación de recursos televisivos tecnológicos. Tiene como base la contextualización de los hechos desencadenados en la UNITINS en el período de su implementación con la utilización de la modalidad educativa tele presencial (y posterior a la EAD) como recursos que permitieron un acelerado proceso de concepción, formulación y ejecución del Proyecto pedagógico del curso Normal Superior tele-presencial, que fue ofrecido inicialmente en el Estado de Tocantins y después, para todo el territorio nacional. La reconstitución de la trayectoria histórica da UNITINS apunta las constantes alteraciones que ocurrieron en los aspectos jurídicos, como también enfatiza las coincidencias entre las políticas de ajustes realizadas por el Estado Brasilero y las exigencias de las políticas internacionales. Estas transforma- 
ces for public universities. The continuous restructuring of the University, either as a public foundation, or as an authority or foundation open to private capital and the beginning of offering of distance courses are in keeping with the neoliberal agenda adopted by the state government and with the establishment of new regulatory standards and substantial changes in the field of Brazilian higher education.

Key words: Higher education. Universities and faculties-Tocantins public policies. Distance education-Tocantins. ciones dejaron marcas evidentes de las políticas de educación superior en el Estado de Tocantins y la política de minimización de los recursos de las universidades publicas. La continua reestructuración de la Universidad, a veces como fundación pública, otras como autarquía o fundación abierta al capital privado y el inicio de la oferta de cursos a distancia estuvieron en consonancia con la agenda neoliberal adoptada por el gobierno estadual y con el establecimiento de nuevos marcos regulatorios y de cambios sustanciales en el campo de la educación superior brasilera.

Palabras-clave: Enseñanza Superior. Universidades e Facultades-Tocantins. Políticas Públicas. Educación a Distancia-Tocantins.

\section{Nelson de Luca Pretto}

Avenida Cons. Pedro Luis, 217/304

CEP: 41950-610 - Salvador - Bahia

E-mail:nelson@pretto.info

www.pretto.info

\section{Isabel C. Auler Pereira}

603 Sul, QHM Lote 15, Alameda 5.

Plano Diretor Sul - Palmas - Est. do Tocantins

CEP: 77.016.366

E-mail: isabel@uft.edu.br 